\title{
JURNAL PERIKANAN

\section{Potensi Lendir Lele (Clarias batrachus) sebagai Saliva Buatan untuk Perawatan Mulut Kering}

\section{The Potential of Catfish Mucus (Clarias batrachus) as Artificial Saliva for Treatment of Dry Mouth (Xerostomia)}

\author{
Zipora Silka Yoretina* ${ }^{* 1}$, Deaoxi Renaschantika Djatumurti ${ }^{2}$, Roissatun Nasikah ${ }^{3}$, Hendri Susanto ${ }^{4}$ \& Heribertus Dedy \\ Kusuma Yulianto ${ }^{5}$ \\ ${ }^{1}$ Pendidikan Dokter Gigi, Fakultas Kedokteran Gigi, Universitas Gadjah Mada, Yogyakarta, Indonesia \\ ${ }^{2}$ Kedokteran Hewan, Fakultas Kedokteran Hewan, Universitas Gadjah Mada, Yogyakarta, Indonesia \\ ${ }^{3}$ Farmasi, Fakultas Farmasi, Universitas Gadjah Mada, Yogyakarta, Indonesia \\ ${ }^{4}$ Departemen Oral Medicine, Fakultas Kedokteran Gigi, Universitas Gadjah Mada, Yogyakarta, Indonesia \\ ${ }^{5}$ Departemen Biomedika, Fakultas Kedokteran Gigi, Universitas Gadjah Mada, Yogyakarta, Indonesia \\ *Penulis korespondensi, email: zipora.silka.y@mail.ugm.ac.id
}

Tanggal Submisi: 25 Desember 2020; Tanggal Revisi: 09 Agustus 2021; Tanggal Penerimaan: 16 November 2021

\begin{abstract}
ABSTRAK Xerostomia merupakan kondisi klinis pasien berupa mulut kering yang dapat meningkakan pertumbuhan jamur Candida albicans penyebab kandidiasis. Penanganan pasien xerostomia dapat dilakukakan dengan pemberian saliva buatan. Lendir lele memiliki karakristik dan kemampuan dalam mengganti fungsi saliva sekaligus sebagai antijamur Candida albicans. Penelitian ini bertujuan untuk mengetahui potensi lendir lele (Clarias batrachus) sebagai saliva buatan untuk perawatan mulut kering. Lendir lele (Clarias batrachus) diekstraksi kemudian diformulasikan menjadi saliva buatan dengan konsentrasi 13,2\%, 14,4\%, dan 17,2\%. Pengujian dilakukan dengan mengukur tegangan permukaan menggunakan indikator besarnya sudut kontak tiap tetesan pada glass slide, mengukur derajat keasaman saliva buatan dengan $\mathrm{pH}$ meter, serta uji daya hambat pertumbuhan Candida albicans dengan metode disc-diffusion. Data kemudian dianalisis menggunakan uji ANOVA satu jalur dan LSD dengan tingkat kepercayaan 95\%. Uji ANOVA menunjukkan perbedaan sudut kontak antara saliva buatan 13,2\%, 14,4\% dan 17,2\% pada glass slide dengan saliva alami dan kontrol positif $(\mathrm{p}<0.05)$, Perbedaan daya hambat terhadap koloni Candida albicans signifikan antara saliva buatan dengan kontrol positif dan saliva alami $(\mathrm{p}<0.05)$. Berdasarkan uji $\mathrm{pH}$, terdapat perbedaan signifikan ketiga konsentrasi saliva buatan $(13,2 ; 14,4 ; 17,2 \%)$ dengan saliva alami dan kontrol positif. Lendir lele berpotensi sebagai bahan pembuatan saliva buatan dan dapat berfungsi sebagai anti-jamur (Candida albicans).
\end{abstract}

Kata kunci: Daya hambat Candida albicans; lendir lele (Clarias batrachus); pH; saliva; sudut kontak

ABSTRACT Xerostomia is a clinical condition of patients complaining of dry mouth. This condition predisposes Candida albicans overgrowth, which causes oral Candidiasis. Patients with dry mouth need some treatment to reduce the symptoms, one of the treatments is artificial saliva treatment. Catfish contain mucus that has characteristics and can become artificial saliva and maybe anti-fungal (Candida albicans). This study aims to determine the potential of catfish mucus (Clarias batrachus) as artificial saliva for treating dry mouth. Catfish mucus (Clarias batrachus) was extracted and then formulated into artificial saliva with $13.2 \%, 14.4 \%$, and $17.2 \%$. The surface tension measurement test by indicating the magnitude of the contact angle of each drop of artificial saliva on the glass slide, measuring the degree of artificial saliva acidity with $\mathrm{pH}$ meter, and the inhibitory test of Candida albicans culture by using the disc diffusion method. The data were analyzed using a one-way ANOVA test and LSD with a 95\% confidence level. ANOVA test showed a difference of contact angle between artificial saliva $13.2 \%, 14.4 \%$, and $17.2 \%$ on a glass slide with natural saliva and positive control $(\mathrm{p}<0.05)$, Differences inhibitory to Candida albicans colony were significant between artificial saliva and positive control and natural saliva $(\mathrm{p}<0.05)$. The $\mathrm{pH}$ test showed significant differences between the three artificial saliva concentrations $(13.2 ; 14.4 ; 17.2 \%)$ with natural saliva and positive controls. Catfish mucus may have the potential to be artificial saliva and may have functioned as an anti-fungal to Candida albicans.

Keywords: Inhibitory effect to Candida albicans; catfish (Clarias batrachus) mucus; pH; saliva; contact angle

\section{PENDAHULUAN}

Mulut kering (xerostomia) merupakan suatu gejala yang umumnya berhubungan dengan berkurangnya sekresi saliva dalam rongga mulut yang disebabkan oleh beberapa faktor. Produksi saliva yang berkurang dapat menyebakan perubahan dalam komposisi saliva yang mengakibatkan sebagian besar fungsi saliva tidak dapat berperan dengan baik. Kondisi tersebut memicu timbulnya beberapa keluhan seperti kesukaran dalam mengunyah atau menelan, kesukaran dalam berbicara, penurunan kepekaan terhadap pengecapan, dan peningkatan kemungkinan terjadinya infeksi oportunistik jamur Candida albicans. Xerostomia tidak selalu disertai dengan penurunan sekresi saliva, akan tetapi sekresi saliva yang menurun lebih dari 50\% dapat menyebabkan beberapa keluhan seperti rasa ketidaknyamanan rongga mulut pada pasien kanker kepala dan leher pasca radioterapi atau kemoterapi. Perawatan terhadap pasien xerostomia biasanya dilakukan dengan meningkatkan 
sekresi dari kelenjar saliva menggunakan obat sialogogue, namun padakondisi xerostomia yang parah, pemberian obat tidak mampu menstimulasi kelenjar saliva dikarenakan terlalu sedikitnya jumlah sel asinar pada kelenjar saliva. Oleh karena itu, pasien harus dirawat dengan pemberian saliva buatan.

Saliva buatan diformulasikan sedemikian rupa sehingga memiliki sifat yang mirip dengan saliva alami manusia, dengan menitikberatkan karakteristik fisiknya mengenai viskositas dan kemampuannya dalam membasahi lapisan rongga mulut. Hal ini dilakukan karena fungsi utama dari saliva adalah sebagai pelumas mukosa mulut. Selain itu, saliva juga memiliki fungsi yang penting dalam sistem pertahanan mukosa terhadap berbagai infeksi mikroorganisme. Dalam kondisi mulut kering, kemungkinan pertumbuhan jamur Candida albicans akan meningkat dan dapat meningkatkan risiko terjadinya kandidiasis oral. Oleh karena itu, saliva buatan juga diharapkan mampu melawan serangan infeksi jamur pada mukosa mulut(Amal etal., 2015).

Lendir merupakan salah satu bahan yang dapat digunakan untuk meniru viskositas saliva alami manusia. Keefektifitasan lendir hewan dalam sifat reologinya telah dikonfirmasi secara obyektif dapat memainkan peranan penting sebagai mucin pada fungsi saliva buatan pada manusia (Park et al, 2007). Hussin et al. (2017) menyatakan bahwa lele dapat menjadi sumber lendir epidermal yang baik. Lendir lele juga dikenal mampu berperan penting dalam mencegah agen infeksi seperti bakteri dan jamur. Lendir mengandung beberapa protease (serine proteases, cycteine protease, metalloproteases, dan typsin like proteases) yang memiliki kemampuan antibakterial yang tinggi, serta telah terbukti menunjukkan ketahanan yang kuat terhadap serangan mikroba (Loganathan et al., 2011). Akan tetapi, hingga saat ini lendir lele belum pernah dimanfaatkan sebagai bahan pembentuk saliva buatan.

Penelitian ini bertujuan untuk mengetahui potensi lendir lele (Clarias batrachus) sebagai saliva buatan. Saliva buatan dengan ekstrak lendir lele diharapkan mampu dikembangkan lebih lanjut untuk mendapatkan paten, sehingga dapat diproduksi secara masal dengan harga yang terjangkau.

\section{BAHAN DAN METODE}

\section{Bahan}

Alat dan bahan yang digunakan dalam penelitian adalah beaker glass, nampan plastik, spatula stainless steel, spuit injeksi, mikrotube, mikropipet dan tip mikropipet, sentrifuge (Eppendorf, Jerman), gelas ukur, timbangan dan kertas timbangan, tabung reaksi, sendok, pemanas air, magnetic stirrer, conical tube, freezer $4^{\circ} \mathrm{C}$ (Sanyo, Jepang), glass slide dilapisi isolasi bolak balik (permukaan hidrofobik), tumpukan balok permukaan datar, kamera digital (Fujifilm XM1), perangkat komputer disertai pengolah gambar ImageJ, aluminium foil, cawan petri, incubator (Sanyo, Jepang), autoclave (Rexall), laminar flow (Thermo Scientific, German), kapas lidi swab, jangka sorong, kawat ose, lampu bunsen, spiritus, korek api, alkohol, Sabouraud Agar, biakan murni Candida albicans, lele spesies Clarias batrachus, aquadest, $\mathrm{NaCl}$ fisiologis (Widatra Bhakti), aquadest pro-injection (Ikaparmindo Putramas), EDTA (Brataco), methylparaben (Brataco), dekstrosa (Brataco), serta saliva.

\section{Metode}

Metode penelitian yang digunakan adalah jenis penelitian eksperimental murni. Ekstrak yang digunakan pada penelitian ini dibuat dari lendir lele yang berspesies Clarias batrachus yang sebelumnya telah diidentifikasi di Laboratorium Taksonomi Fakultas Biologi UGM. Ekstraksi lendir lele dilakukan di Laboratorium Biokimia Fakultas Kedokteran Hewan UGM. Lele dicuci terlebih dahulu dengan air sulingan untuk membersihkan permukaan tubuhnya, kemudian distimulasi agar memproduksi lendir yang lebih banyak dengan cara dikeluarkan dari air selama beberapa menit. Lendir dikoleksi dengan cara dilakukan swab mukosa epidermal lele bagian dorsal menggunakan spatula. Kumpulan lendir di atas spatula kemudian diambil menggunakan spuit injeksi dan dimasukkan ke dalam mikrotube. Lendir yang sudah terkumpul dicampurkan dengan $\mathrm{NaCl}$ fisiologis dengan perbandingan 1:1 untuk kemudian dilakukan sentrifugasi dengan kecepatan 5000 rpm selama 15 menit. Hasil sentrifugasi yang digunakan adalah lapisan supernatant yang berada di bagian atas.

Saliva buatan diproduksi dengan terlebih dahulu melarutkan 0,1\% methylparaben (nipagin) dalam aquadest pro-injection dengan cara dipanaskan kemudian dihomogenisasi menggunakan vortex mixer. Larutan ditunggu hingga dingin kemudian dicampurkan 4,69\% dextrosa, 0,05\% EDTA, serta ekstrak lendir lele konsentrasi 13,2\%, 14,4\%, dan 17,2\%.

Pengujian dilakukan dengan mengukur tegangan permukaan menggunakan indikator besarnya sudut kontak sebanyak 5 kali pada tiap sampel. Saliva buatan konsentrasi 13,2\%, 14,4\%, 17,2\% diteteskan sebesar 60 mikroliter menggunakan mikropipet diatas glass slide kemudian dilakukan pengambilan foto dengan kamera digital (Fujifilm XM1). Sebagai pembanding, dilakukan pula uji terhadap saliva alami probandus laki-laki sehat, saliva alami probandus perempuan sehat, serta Mucosamin yang merupakan produk saliva buatan yang telah beredar dipasaran. Pengukuran sudut kontak dilakukan setelah data hasil foto dimasukkan pada aplikasi ImageJ sehingga didapatkan besar sudut kontak dari kedua sisi droplet.

Uji daya hambat saliva buatan terhadap pertumbuhan Candida albicans dilakukan dengan metode disc-diffusion untuk melihat kemampuan anti-jamurnya. Dilakukan penetesan 20 mikroliter saliva buatan konsentrasi 13,2\%, 14,4\%, 17,2\% dalam disc, kemudian disc diletakkan pada koloni Candida albicans yang telah dikulturkan di media SDA (Sabouraud Dextrose Agar) dan diinkubasi pada suhu $37^{\circ}$ selama 24 jam. Sebagai pembanding, dilakukan pula uji terhadap Nystatin dan Mucosamin. Selain itu, saliva buatan dilakukan pengujian $\mathrm{pH}$ menggunakan $\mathrm{pH}$ meter. Semua uji ini dilakukan di Laboratorium Riset Terpadu Fakultas Kedokteran Gigi UGM.

Data yang didapatkan dari tiap pengujian kemudian dianalisis secara statistik dengan menggunakan Analysis of Variance (ANOVA) satu jalur dan dilanjutkan dengan uji LSD dengan tingkat kepercayaan 95\%.

\section{HASIL DAN PEMBAHASAN}

\section{Hasil}

Hasil penelitian sudut kontak antara glass slide dan tiga konsentrasi saliva buatan (13,2; 14,4; 17,2\%), saliva alami probandus, serta Mucosamin dapat dilihat pada Gambar 1.

Sudut kontak saliva buatan lendir lele memiliki nilai rerata sudut kontak yang relatif mirip dengan sudut kontak saliva alami manusia. Hasil uji ANOVA satu jalur menunjukkan 
bahwa terdapat perbedaan yang bermakna pada sudut kontak sebagai indikator tegangan permukaan sampel saliva buatan yang diuji $(p<0,05)$.

Pada uji LSD yang dilakukan, didapatkan hasil seperti pada Tabel 1 yang menunjukkan bahwa ketiga saliva buatan dengan konsentrasi yang berbeda $(13,2 ; 14,4 ; 17,2 \%)$ memiliki perbedaan sudut kontak yang signifikan terhadap Mucosamin. Apabila dibandingkan dengan saliva alami probandus laki-laki sehat, saliva buatan dengan konsentrasi $17,2 \%$ dan Mucosamin memiliki perbedaan sudut kontak yang signifikan. Sedangkan, apabila dibandingkan dengan saliva alami probandus perempuan sehat, seluruh konsentrasi saliva buatan beserta Mucosamin memiliki perbedaan sudut kontak yang cukup signifikan $(p<0,05)$. Hasil penelitian besar zona hambat yang terbentuk pada media Sabouraud Dextrose Agar dapat dilihat pada Gambar 2. Saliva buatan lendir lele memiliki daya hambat lebih tinggi dibandingkan kontrol Mucosamin dan Nystatin. Hasil uji ANOVA menunjukkan bahwa perbedaan besarnya zona hambat yang terbentuk signifikan antara saliva buatan lendir lele, kontrol Mucosamin, serta obat anti-jamur Nystatin $(p<0,05)$.

Berdasarkan uji LSD terhadap daya hambat Candida albicans saliva buatan lendir lelel dan kontrol yang dapat dilihat pada Tabel 2, hasil menunjukan bahwa apabila

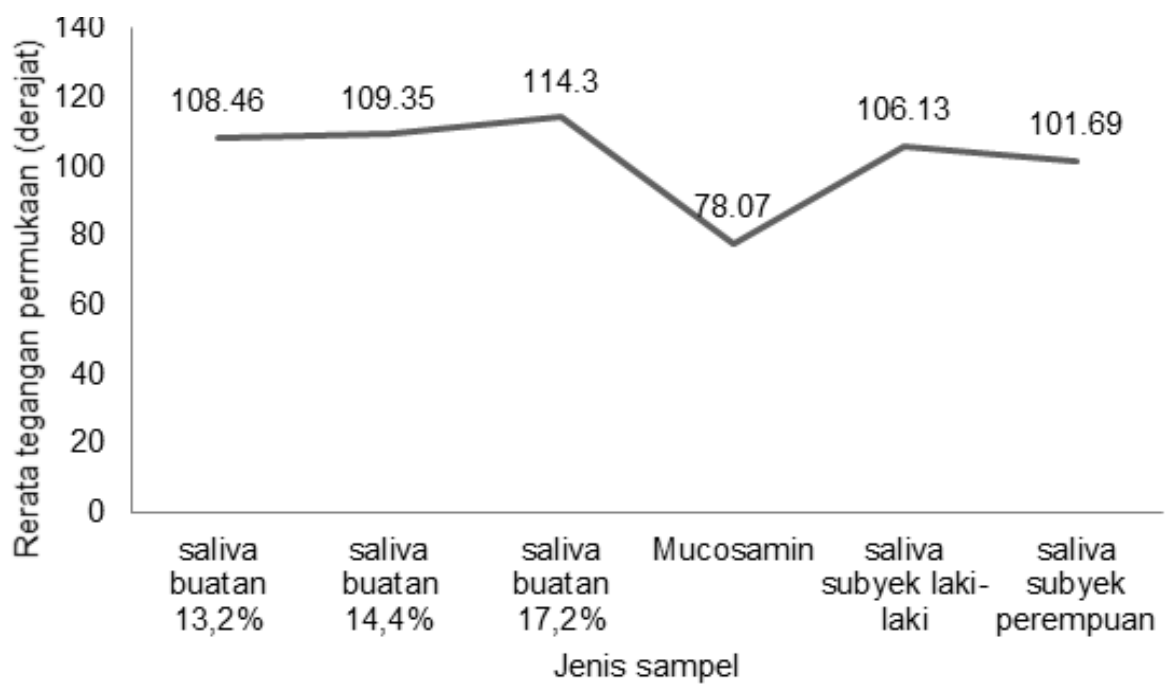

Gambar 1. Perbandingan rerata tegangan permukaan antara saliva buatan lendir lele dan kontrol.

Tabel 1. Hasil analisis Post Hoc LSD antara tegangan permukaan saliva buatan lendir lele dan kontrol.

\begin{tabular}{llllll}
\hline Variabel & Saliva buatan 13,2\% & Saliva buatan 14,4\% & Saliva buatan 17,2\% & Mucosamin & Saliva laki-laki \\
\hline Saliva buatan 13,2\% & & & & & \\
Saliva buatan 14,4\% & 0,742 & & & & \\
Saliva buatan 17,2\% & 0,037 & 0,073 & 0,000 & & \\
Mucosamin & 0,000 & 0,000 & 0,005 & 0,000 & \\
Saliva laki-laki & 0,386 & 0,236 & 0,000 & 0,000 & 0,107 \\
Saliva perempuan & 0,017 & 0,008 & & & \\
\hline
\end{tabular}

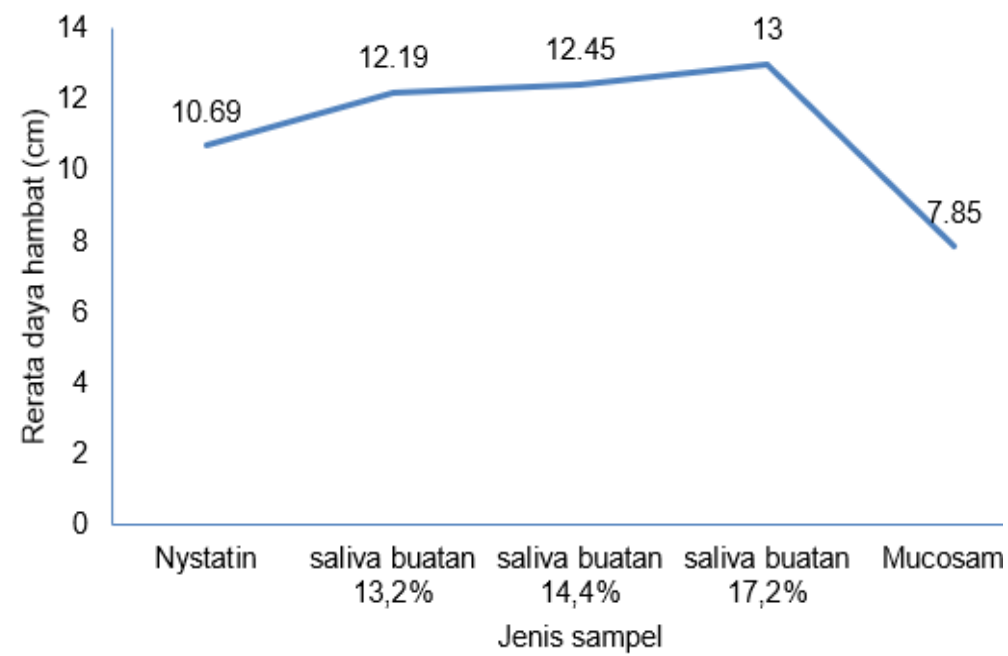

Gambar 2. Perbandingan rerata daya hambat Candida albicans antara saliva buatan lendir lele dan kontrol. 
Tabel 2. Hasil analisis Post Hoc LSD antara daya hambat Candida albicans saliva buatan lendir lele dan kontrol.

\begin{tabular}{llllll}
\hline Variabel & Saliva buatan 13,2\% & Saliva buatan 14,4\% & Saliva buatan 17,2\% & Mucosamin & Nystatin \\
\hline Saliva buatan 13,2\% & & & & \\
Saliva buatan 14,4\% & 0,736 & & & \\
Saliva buatan 17,2\% & 0,299 & 0,471 & & \\
Mucosamin & 0,000 & 0,000 & 0,000 & 0,003 \\
Nystatin & 0,072 & 0,040 & 0,011 & \\
\hline
\end{tabular}

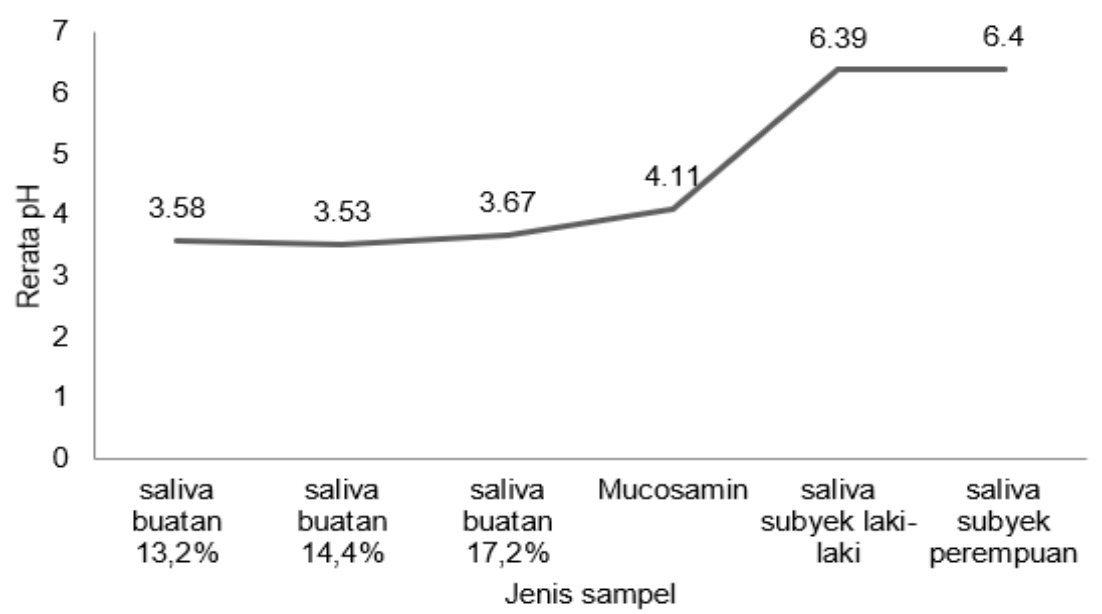

Gambar 3. Perbandingan rerata pH antara saliva buatan lendir lele dan kontrol.

Tabel 3. Hasil analisis Post Hoc LSD antara pH saliva buatan lendir lele dan kontrol.

\begin{tabular}{llllll}
\hline Variabel & Saliva buatan 13,2\% & Saliva buatan 14,4\% & Saliva buatan 17,2\% & Mucosamin & Saliva laki-laki \\
\hline Saliva buatan 13,2\% & & & & & \\
Saliva buatan 14,4\% & 0,430 & & & & \\
Saliva buatan 17,2\% & 0,226 & 0,058 & 0,000 & & \\
Mucosamin & 0,000 & 0,000 & 0,000 & 0,000 & 0,881 \\
Saliva laki-laki & 0,000 & 0,000 & 0,000 & 0,000 & 0 \\
Saliva perempuan & 0,000 & 0,000 & & & \\
\hline
\end{tabular}

dibandingkan dengan Nystatin, salah satu obat antijamur, saliva buatan konsentrasi $14,4 \%$ dan $17,2 \%$ menunjukkan perbedaan yang signifikan $(p<0,05)$.

Berdarkan uji $\mathrm{pH}$ yang dilakukan menggunakan $\mathrm{pH}$ meter terhadap tiap-tiap sampel, didapatkan hasil seperti pada Gambar 3 yang menunjukkan bahwa ketiga saliva buatan yang diproduksi memiliki pH yang tergolong asam, namun tidakjauh berbeda dari Mucosamin.

Hasil yang didapatkan dari uji LSD terhadap $\mathrm{pH}$ saliva buatan lendir lele dan kontrol dapat dilihat seperti pada Tabel 3. Meskipun nilai derajat keasaman $(\mathrm{pH})$ saliva buatan semua konsentrsi lebih rendah dibandingkan dengan saliva alami laki-laki dan perempuan namun memiliki kemiripan nilai $\mathrm{pH}$ dengan saliva buatan kontrol Mucosamin. Hasil analisis LSD menunjukkan bahwa semua konsentrasi saliva buatan lendir lele memiliki perbedaan yang signifikan dengan kontrol saliva alami laki-laki dan perempuan dan Mucosamin ( $p<0.05)$.

\section{Pembahasan}

Penelitian ini merupakan penelitian pertama yang meneliti potensi ekstrak lendir lele Clarias batrachus sebagai saliva buatan untuk alternatif perawatan mulut kering. Lendir lele merupakan jenis mukus yang dihasilkan oleh lele untuk perlindungan lele terhadap trauma atau ancaman dari luar. Kemiripan sifat fisik lendir lele dengan saliva dapat ditunjukkan dalam penelitian melalui uji tegangan permukaan yang menghasilkan kemiripan antara besar sudut kontak saliva buatan lendir lele dan saliva probandus laki-laki dan perempuan pada glass slide. Hal ini menunjukkan bahwa saliva buatan yang mengandung ekstrak lendir lele memiliki kemampuan dalam membasahi mukosa mulut. Menurut Putriyanti (2012), saliva berperan dalam sistem lubrikasi rongga mulut. Dengan kemampuan saliva sebagai lubrikasi, maka risiko terlukanya mukosa mulut akibat makanan yang kita kunyah akan terminimalisir. Pada pasien dengan keluhan mulut kering, kurang atau tidak adanya saliva akan menimbulkan kesulitan dalam mengunyah makanan. Makanan menjadi penting dalam memenuhi kebutuhan nutrisi untuk meningkatkan proses penyembuhan, terutama pada pasien pasca kemoterapi atau radioterapi kanker kepala dan leher (Suprianto \& Subagyo, 2011).

Penelitian ini juga menguji daya hambat saliva buatan yang terbuat dari ekstrak lendir lele pada pertumbuhan jamur Candida albicans. Kondisi mulut kering dapat menjadi faktor predisposisi terhadap pertumbuhan jamur Candida albicans 
pada mukosa mulut, yang dapat menimbulkan mukositis, memperparah keluhan kondisi mulut kering, serta menurunkan kualitas hidup penderitanya (Suprianto \& Subagyo, 2011; Surjadi \& Amtha, 2012). Penelitian ini menunjukkan bahwa saliva buatan ekstrak lendir lele memiliki daya hambat terhadap jamur Candida albicans. Bahkan, daya hambat ekstrak lendir lele memiliki kemampuan yang lebih tinggi dibandingkan dengan obat antijamur Nystatin yang sering digunakan sebagai antijamur pada kasus kandidiasis oral (Hardjono \& Subagyo, 2011). Selain itu, saliva buatan lendir lele juga memiliki daya hambat lebih tinggi dibandingkan Mucosamin yang merupakan saliva buatan sintetis yang beredar di pasaran, sehingga menjadi salah satu keunggulan dari saliva buatan lendir lele.

Penelitian menunjukkan nilai derajat keasaman $(\mathrm{pH})$ saliva buatan lendir lele lebih rendah dibandingkan dengan saliva alami manusia dan saliva buatan Mucosamin. Akan tetapi, sifat keasaman saliva buatan lendir lele dan saliva buatan Mucosamin relatif tidak jauh berbeda. Sifat keasaman saliva buatan lendir lele tentunya masih merupakan faktor yang bisa dimodifikasi dengan menambahkan kandungan bahan tambahan seperti perasa untuk menjadikan derajat keasaman menjadi lebih tinggi, sehingga lebih nyaman untuk dipakai (Kasuma, 2015). Derajat keasaman saliva buatan lendir lele yang rendah dapat diakibatkan oleh rendahnya konsentrasi lendir lele yang dipakai pada penelitian, sehingga perlu dilakukan penelitian lebih lanjut untuk mendapatkan saliva buatan yang lebih baik.

\section{KESIMPULAN DAN SARAN}

\section{Kesimpulan}

Lendir lele berpotensi sebagai bahan dalam pembuatan saliva buatan yang dapat dilihat dari besarnya tegangan permukaan yang menyerupai saliva alami, memiliki kemampuan sebagai antijamur, serta $\mathrm{pH}$ yang relatif tidak berbeda jauh dengan Mucosamin.

\section{Saran}

Perlu dilakukan penelitian lebih lanjut guna memperoleh saliva buatan yang lebih optimal, untuk kemudian dilanjutkan dengan pengajuan hak paten dan pengembangan produksi saliva buatan.

\section{UCAPAN TERIMA KASIH}

Kami mengucapkan terima kasih kepada Kementrian Riset Teknologi dan Pendidikan Tinggi (KEMENRISTEKDIKTI) Republik Indonesia yang telah mendanai penelitian ini pada tahun 2018.

\section{DAFTAR PUSTAKA}

Amal, A.S.S., S. Hussain \& M.A. Jalaluddin. 2015. Preparation of artificial saliva formulation. ICB Pharma. 2: 6-12.

Hardjono, S.B.W \& G. Subagyo. 2011. Kandidiasis di mulut akibat khemoterapi dan penatalaksanaanya. Majalah Kedokteran Gigi. 18 (2): 173-177.

Hussin, N.M., S.M. Shaarani, M.R. Sulaiman, A.H. Ahmad \& C.S. Vairappan. 2017. Chemical composition and antioxidant activities of catfish epidermal mucus. Journal of Advanced Agricultural Technologies. 4 (1): 73-77.
Kasuma, N. 2015. Fisiologi dan Patologi Saliva. Andalas University Press. Padang.

Loganathan, K., M. Muniyan, A.A. Prakash, P.S. Raja \& M. Prakash. 2011. Studies on the role of mucus from Clarias batrachus (Linn) against selected microbes. International Journal of Pharmaceutical Application. 2 (3): 202-206.

Park, M.S., J.W. Chung, Y.K. Kim, S.C. Chung \& H.S. Kho. 2007. Viscosity and wettability of animal mucin solutions and human saliva. Oral Diseases. 13: 181-186.

Putriyanti, F., E. Herda \& A. Soufyan. 2012. Pengaruh saliva buatan terhadap diametral tensile strength micro-fine hybrid resin composite yang direndam dalam minuman isotonik. Jurnal PDGI. 61(1): 43-7.

Suprianto, S \& G. Subagyo. 2011. Perawatan kandidiasis pseudomembran akut dan mukositis oral pada penderita kanker nasofaring yang menerima khemoterapi dan radioterapi. Majalah Kedokteran Gigi. 18 (2): 182-186.

Surjadi, N \& R. Amtha. 2012. Radiotherapy reduced salivary flow rate and might induce $C$. albicans infection. Journal of Dentistry Indonesia. 19 (1): 14-19. 